
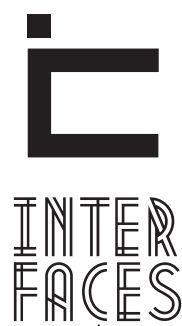

CIENTÍFICAS

EDUCAÇ̃̃o

\title{
A PRESENÇA FEMININA NA INSTITUIÇÃO DO ENSINO SUPERIOR NO INTERIOR DA BAHIA'
}

Ana Maria Fontes dos Santos ${ }^{2}$

\section{RESUMO}

Neste artigo procura-se enfocar as diferentes trajetórias de inserção de professoras licenciadas que protagonizaram os primórdios da implantação do ensino superior estadual em Feira de Santana, Bahia. Nesta cidade, em 1968, passou a funcionar a primeira faculdade de formação de professores destinada ao interior do Estado, implantada como Faculdade Estadual de Educação (FEEFS). As referências centrais do estudo são os percursos de três professoras que adentraram ao campo universitário interiorano a partir de diferentes lugares no campo científico e político, identificadas como portadoras de diferentes formas de capital simbólico no âmbito das lutas de instituição do referido campo. 0 fio condutor da abordagem enfatiza os matizes de sombreamento e exposição de agentes femininos enquanto precursoras, como se situavam no contexto das relações de força que permearam a implantação do ensino superior na cidade. Conclui-se que a inserção da mulher com formação em licenciatura no mercado de trabalho foi uma necessidade imposta por fatores econômicos do período. Ao lado de fontes variadas, a perspectiva metodológica contempla a memória, referenciada em autores da história cultural e nos estudos de Bourdieu na abordagem dos conceitos de campo e de capital.

\section{PALAVRAS-CHAVE}

Ensino Superior. História da Educação. Trajetórias Femininas 


\section{ABSTRACT}

This article seeks to focus on the different trajectories insertion licensed teachers who staged the beginnings of higher education statewide deployment in Feira de Santana, Bahia. In this city, in 1968, began operating the first college for teacher education aimed at the state, deployed as State College of Education (FEEFS). References main study tours are three teachers who had entered the university campus backwoods from different places in the scientific and political, identified as suffering from different forms of symbolic capital within the institution struggles of that field. The guiding approach emphasizes the nuances of shading and exposure while female agents precursors, as stood in the context of power relations that permeated the implementation of higher education in the city. It is concluded that the inclusion of women with undergraduate training in the labor market was a necessity imposed by economic period. Beside various sources, the methodological approach contemplates the memory referenced authors in the history and cultural studies Bourdieu in addressing the concepts of field and capital.

\section{KEYWORDS}

Higher Education. History of Education. Female Trajectories

\section{INTRODUCÇÃO}

No contexto das relações de força que permearam a implantação do campo educacional superior no interior baiano, iniciado em Feira de Santana pela via pública estadual, desenrolaram-se ações partidas de diferentes campos relacionados ao poder, sobretudo sob a forma de poder simbólico, conforme a discus-

\section{RESUMEN}

Este artículo pretende centrarse en las diferentes trayectorias de inserción de los profesores graduados que dieron inicio al mayor despliegue de la implantación educacional, a nivel Estatal, en la ciudad de Feira de Santana, en Bahía. En ésta ciudad, en 1968, comenzó a funcionar la primera escuela para la formación del profesorado del interior de la Provincia, implantado como Faculdade Estadual de Educacãon (FEEFS). Las principales referencias de estudio, son las trayectorias de tres profesoras que habían entrado en la selva virgen del campus universitario de diferentes sitios de la lucha científica y política, identificadas como portadoras de las diferentes formas de capital simbólico dentro de la institución de ese campo. El hilo conductor del abordaje, enfoca los matices de sombras y exposición de los agentes femeninos precursores, que estaban en el contexto de las relaciones de poder que impregnaron la implementación de la educación superior en la ciudad. Se concluye que, la inclusión de las mujeres con formación universitaria en el mercado de trabajo es una necesidad impuesta por el período económico. Junto a diversas fuentes, la metodología contempla a los autores referenciados en la memoria, historia y estudios culturales de Bourdieu para hacer frente a los conceptos de campo y de capital.

\section{PALABRAS CLAVE}

Educación Superior. Historia de la Educación. Trayectorias Femeninas

são de Bourdieu (2005), que envolveriam a inserção de protagonistas mulheres nos momentos cruciais do processo de institucionalização. A interiorização do ensino superior na Bahia, iniciada em 1968, tinha como foco principal atender as necessidades imediatas do modelo econômico que se implantava no Brasil, 
ao qual se atrelava o incremento da industrialização no Estado, com a implantação do Centro Industrial de Aratu (CIA) e, em Feira de Santana, com a criação do Centro de Desenvolvimento Industrial (Cedin) para incrementar a industrialização no interior.

0 ambiente de ditadura militar, sobretudo a partir de 1968, com a edição do Ato Institucional n 5 , que coincidiu com a implantação da Faculdade Estadual de Educação em Feira de Santana, reforçaria a instância formal de poder. Contudo, as especificidades do campo educacional superior levariam em conta a apropriação de diferentes formas de capital social e capital cultural por parte das agentes em foco. Assim, investigação sobre as memórias e as histórias dos principais agentes que estiveram empenhados nas lutas pela interiorização do ensino superior na Bahia, na década de sessenta do século passado, trouxe à tona personagens femininos, que perante os lugares sociais ocupados pelas mesmas, situavam-se, ou eram postas, às sombras das principais lideranças, no âmbito das lutas de instituição do referido campo.

Aqui são abordadas as diferentes trajetórias de três professoras nos ritos de instituição (BOURDIEU, 1996) do ensino superior em Feira de Santana. São elas: Yara Cunha Pires; Maria Cristina Oliveira de Menezes; e Zélia Maria Caribé Nunes Marques. Além de fazerem parte do grupo de professores que deu início ao ensino superior público interiorano, através da Faculdade Estadual de Educação de Feira de Santana (FEEFS), são também originárias da cidade. A principal identidade entre as mesmas diz respeito às suas formações acadêmicas: as três à época eram licenciadas, egressas da Faculdade Filosofia Ciências e Letras da Universidade da Bahia. No entanto, a inserção das mesmas no referido campo educacional desenhava as contradições e tensões, presentes no processo da implantação do ensino superior público no interior baiano.

Este trabalho apóia-se, principalmente, no suporte teórico elaborado por Pierre Bourdieu (1996 e 2005), com destaque o conceito de campo. Na perspectiva desse autor os campos são considerados como sendo os âmbitos onde se desenrolam as práticas sociais mais ou menos padronizadas, tratados como espaços relativamente autônomos de forças objetivas e lutas, sob formas específicas de autoridade. Os campos possuem especificidades próprias que os caracterizam e são definidos de acordo com seus valores internos, em suas dinâmicas, regras e capitais específicos (SANTOS, 2011). A posição das pessoas nesses espaços sociais, enquanto campos específicos, se articula a partir da distribuição desigual de diferentes formas de capital (social ${ }^{1}$, cultural, simbólico, econômico). Sobre o capital cultural, Bourdieu elucida que o mesmo foi elaborado como uma tentativa em romper com os pressupostos inerentes, tanto à visão de senso comum "que considera o sucesso ou fracasso escolar como efeito das 'aptidões' naturais, quanto às teorias do 'capital humano"' (BOURDIEU, 1998, p. 73). Neste sentido explicita sobre a complexidade do que entende por capital cultural, que envolve implicações não apenas sociológicas, mas, sobretudo, históricas, conforme saliente pode existir sob três formas:

\begin{abstract}
no estado incorporado, ou seja, sob a forma de disposições duráveis do organismo; no estado objetivado, sob a forma de bens culturais [...]; e, no estado institucionalizado, forma de objetivação que é preciso colocar à parte porque, como se observa em relação ao capital cultural - de que é, supostamente, a garantia - propriedades inteiramente originais (BOURDIEU, 1998, p.74).
\end{abstract}

Importante salientar que os conceitos em Bourdieu são dinâmicos, ao longo de sua obra, os mesmos foram discutidos e/ou reelaboras ou ampliados. A forma aqui exposta procura atribuir alguns significados relativos ao trabalho empreendido nesta pesquisa.

De posse desses referenciais, o objetivo é o de compreender as relações entre os agentes sociais e

\footnotetext{
1 Por capital social pode ser entendido como "o conjunto de recursos atuais ou potenciais que estão ligados à posse de uma rede durável de relações mais ou menos institucionalizadas de interconhecimento e de inter-reconhecimento". Assim, as relações estabelecidas entre os agentes são proporcionadas pela vinculação a um grupo, conferindo aos mesmos, ligações permanentes e úteis (BOURDIEU, 1998, p. 67).
} 
os mecanismos de conquista de legitimidade por parte dos agentes femininos nos processos de ingresso e participação do campo em estudo. Assim, a partir das premissas teóricas de Bourdieu, levantou-se o questionamento sobre a forma do ingresso de determinados agentes femininos no processo de implantação do campo educacional superior em Feira de Santana. Quais os requisitos e processos que as teriam levado ao campo universitário em estudo, uma vez que o sombreamento parece ser a marca de suas participações nos momentos iniciais daquele campo educacional?

Do ponto de vista metodológico buscamos apoio em Ginzburg (2002), que adverte sobre a importância da abordagem das fontes, no sentido de compreender as distorções que elas encerram. De acordo com esse autor, na avaliação das provas documentais (no sentido amplo) cabe ao historiador "recordar que todo ponto de vista sobre a realidade, além de ser intrinsecamente seletivo e parcial, depende das relações de força que condicionam [...] a imagem total que uma sociedade deixa de si” (p. 43), chamando atenção, portanto, sobre os recursos heurísticos necessários ao fazer da história.

No tratamento das fontes orais cotejamos algumas contribuições da História Oral, incorporando discussões sobre a memória, enquanto algo construído e reconstruído em função das experiências da pessoa que fala, sempre considerando os silêncios e o esquecimento, enquanto parte da dialética que compõe a memória social. Sobre a metodologia da História Oral nos apoiamos em Thompson, Alister (1997), e em Portelli (1996), entre outros que fornecem contribuições essenciais para melhor compreender a utilização da fonte oral em nosso trabalho. As fontes utilizadas foram colhidas no acervo Particular de Fernando Pinto Queiroz, no livro de memórias Reminicências de autoria de Geraldo Leite (Feira de Santana, UEFS: 2007) em documentos oficiais, mas privilegiando a entrevista oral enquanto trabalhos da memória.

\section{INGRESSO DAS PROFESSORAS CITADAS NO CONTEXTO DA ORGANIZAÇÃO DO CAMPO UNI- VERSITÁRIO DE FEIRA DE SANTANA}

A criação, em 1963, da Associação Educacional Desembargador Filinto Bastos, por Fernando Pinto de Queiroz com o apoio logístico do deputado federal Wilson Falcão, incrementaria uma proposta da Faculdade de Filosofia para Feira de Santana, contando também com o apoio fundamental de lideranças políticas do município, entre os quais o deputado estadual Áureo de Oliveira Filho.

A Associação Educacional Desembargador Filinto Bastos inscreve na cidade a perspectiva real de criação de curso universitário, sob a liderança do intelectual Fernando Pinto Queiroz, e mobilizou os diversos setores sociais e outros recursos possíveis com vistas à execução do projeto de Faculdade de Filosofia. Quando Queiroz discorreu sobre o recrutamento de professores que atuavam na Faculdade de Filosofia da UBA para lecionarem na Faculdade de Feira de Santana, citou a participação da então estudante Yara Cunha. Vejamos:

[...] Graças a quê? Graças também ao trabalho, à colaboração de Yara [Cunha], como aluna da Faculdade de Filosofia, Curso de Pedagogia daquela época, passou a ser nossa porta voz, para fazer contato com professores que nós falávamos e que também ia contactando por lá, e como Geraldo [Leite] já havia se mudado 
para Salvador ele também era um elemento de contato (Palestra proferida por Fernando Queiroz, UEFS, 27/05/1996).

$\mathrm{Na}$ ocasião dessa palestra, Queiroz apresentou uma documentação, conforme disse: "Eu tenho aqui um memorando para Yara, muito interessante 'Cuide de fazer isso, cobre de Iraci [Picanço, profa. da UBA], isso, isso, e outras coisas mais' - é a participação dela”. No relato abaixo, da professora Yara Cunha Pires, vemos seu envolvimento nesses momentos iniciais de luta por ensino superior em Feira de Santana, ainda como estudante secundarista:

[...], na política estudantil, eu tive, ainda aluna do Instituto de Educação Gastão Guimarães, um contato com um personagem importantíssimo na minha vida e os vínculos que nós tivemos posteriormente, que foi Fernando Pinto, eu era presidente do grêmio, era membro da AFES ${ }^{2}$, e Fernando estava promovendo os debates para a criação de uma Faculdade de Filosofia em Feira e ele tinha um programa de rádio, então ele nos convidou para participar de um debate nesse programa de rádio, onde já se discutia a criação do ensino superior em Feira, [...]. O programa de rádio era "Interesses da Comunidade", era um programa promovido pelo Lions Club e Fernando era uma figura importantíssima na comunidade, um homem de grande atuação, então ele nos levou, levou as lideranças estudantis, os presidentes dos grêmios, [...] e depois teve desdobramentos porque, quando eu fui para a Faculdade de Filosofia, eu continuei mantendo esses contatos (Yara Cunha Pires, entrevista concedida em 09/03/2009).

Oriunda do movimento estudantil dos anos sessenta e envolvida nos movimentos de luta por implantação de ensino superior em Feira de Santana, que duraria até o alvorecer do ano de 1968, a referida professora ingressou na FEEFS, como professora de Psicologia da Educação, ainda no processo de organização do primeiro vestibular. Ocasião em que, ao lado de sua antiga professora dessa disciplina, Alice Costa, ajudou na elaboração e aplicação de testes psicológicos adotados naquele vestibular. Perguntada sobre o porquê de sua contratação para essa instituição respondeu:

2 Associação Feirense de Estudantes Secundaristas
Bom, eu já tinha uma história de estar envolvida com aquelas pessoas todas na luta de Fernando Pinto pela Faculdade de Filosofia, então eu já era super conhecida na Faculdade de Filosofia da UFBA, naquele tempo Universidade da Bahia, então eu já tinha assim, aqueles professores já me conheciam, quando eu terminei eu fui considerada uma aluna muito boa, tanto que fui convidada para ficar lá na Faculdade de Filosofia. A minha primeira proposta foi ficar na Faculdade de Filosofia, eu ainda fiz parte de um grupo com Maria Angélica Matos [...]. Então eu comecei aí.[...mas], eu tive que declinar. Quando foi em 1967, ano que nós iríamos iniciar, o ano de 1966 foi então de preparação, o de 1967 eu deveria começar, aí foi o ano que eu decidi voltar para Feira, aí eu tive que declinar dessa indicação (Yara Cunha Pires, entrevista concedida em 9/03/2009).

A leitura da longa entrevista concedida por essa professora, para esta pesquisa, permite inferir que a mesma teve como foco, em sua trajetória escolar, o exercício docente: filha de professora, reconhecida por ela, como aplicada ao ofício, fez o curso de magistério primário e logo ingressou no ensino superior, concluindo a licenciatura em Pedagogia em1965 e o bacharelado em 1966, ano em que já se preparava para ser professora da Universidade. Também nesse ano de 1966 teve início sua carreira de docente no Instituto Central de Educação Isaías Alves, em Salvador ${ }^{3}$. Sobre o concurso público que a referida professora submeteu-se em 1968, para professora do ensino médio, assim relatou:

No concurso de 1968 também concorreram pessoas que já tinham uma certa expressão no ensino, até pessoas que ensinavam no curso superior, como professor Rodrigues, Mercedes Mendonça [...], foi uma corrida, anos e anos e anos que não tinha concurso para o Estado, então muita gente foi, mesmo professores que já ensinavam, como João Rodrigues que era professor da [Universidade] Católica, Mercedes que também já estava na [Universidade] Federal, concorreram, e eu passei em segundo lugar, na minha frente só profes-

3 Sobre a forma de ingresso nesse Instituto disse: "naquele tempo não era uma contratação, se fazia uma nomeação provisória que se chamava 'nomeação interina', até que se fosse efetivado. E em 1968 houve o concurso promovido por Navarro de Brito [então Secretário Estadual da Educação e Cultura] e foi aí que eu ingressei no magistério secundário" (Yara Cunha Pires, entrevista, op.cit.). 
sor Rodrigues, professor da Católica muito conhecido, e Mercedes, que já era da Federal, ficou em terceiro lugar, eu fiquei em segundo lugar (Yara Cunha Pires, entrevista concedida em 9/03/2009).

Observe-se que nesse período era comum às universitárias da Faculdade de Filosofia, sobretudo dos cursos de Letras e Pedagogia, e em particular aquelas oriundas das camadas sociais mais elevadas, como era o caso das agentes aqui elencadas, assumirem o casamento como destino imediato e não a vida profissional. Para muitas delas, o exercício profissional se deu muito mais em decorrência das mudanças socioeconômicas verificadas no País depois de 1964, tanto no sentido da ampliação do mercado de trabalho que atraía maiores contingentes femininos com formação universitária, quanto no sentido de complemento da renda familiar (geralmente, esses dois aspectos articulados atraiam mulheres ao mercado de trabalho).

Os indícios apontam que a professora Yara Cunha Pires ingressou no ofício de professora e na FEEFS cumprindo uma trajetória profissional que a mesma havia traçado. Razão pela qual ingressava no campo universitário feirense, a partir de capitais social e cultural acumulados, tanto nas lutas pela interiorização da universidade, e, principalmente, em sua recente trajetória universitária ("considerada aluna muito boa”, cf. declinou acima), que the renderia credenciamento na própria instituição em que foi formada, sendo que sua passagem para a faculdade feirense estaria praticamente traçada. Ou seja, não foi à toa que a então jovem professora foi recrutada para proferir a "primeira aula"4 da FEEFS.

A FEEFS foi a resposta do governo estadual em substituição à demanda local por Faculdade de Filosofia. "Os tempos" eram outros, como foi dito, de ditadura militar. A gestão do governador Luiz Viana Filho,

$4 \mathrm{Na}$ inauguração dessa primeira faculdade estadual interiorana, para contrariedade dos agentes no poder não houve "aula inaugural", com estardalhaços e presença de autoridades governamentais, em razão das improvisações que cercaram o início da implantação, obrigando a direção a "inaugurá-la” no chão da aula, em 19/09/1968 (Santos, 2011). na contramão das demandas locais (que vislumbrava a execução de passos para se atingir uma universidade), elaborou o Plano Integral de Educação e Cultura (Piec), a partir do qual se implantaram licenciaturas curtas em algumas cidades do interior para formar professores, que atenderiam a explosiva demanda do "primeiro ciclo" (antigo ginásio). A denominação "Faculdade de Educação" seria a fórmula encontrada para aplacar os interesses locais, posto que, duas outras dessas instituições, implantadas logo depois em outros municípios, foram criadas como "Faculdade de Formação de Professores”. Assim, pouco mais de um ano após a criação da FEEFS, por força das pressões locais, a gestão estadual assumiria a implantação de universidade em Feira de Santana5. "Em 28 de novembro de 1969 o Governo do Estado autorizou a Secretaria de Educação e Cultura a promover os meios necessários à instalação e funcionamento da Fundação Universidade de Feira de Santana, constituindo uma comissão [...]" (Leite, 2007) Dela faziam parte, além de Geraldo Leite, Joaquim Vieira de Azevedo Coutinho Neto (representante da SEC) e Maria Cristina de Oliveira Menezes. Sobre a participação desta professora na comissão, é possível deduzir do comentário escrito por Geraldo Leite (2007), em suas memórias, que a mesma encontrava-se alheia ao campo universitário que se intencionava implantar. Segundo ele,

Nos primeiros dias de dezembro de 1969, a Profa. Maria Cristina de Oliveira Menezes, um dos membros da comissão designada pelo decreto 21.583 , de 28 de novembro, telefonou-me, surpresa com a notícia de que estava incluída na referida comissão, cuja finalidade era elaborar o anteprojeto para implantação da Fundação [...] Relatei de modo aligeirado, o contato que Wilson Falcão e eu tivemos com o governador [...] no dia 26 de novembro e a decisão de ser criada a Universidade Estadual de Feira de Santana. Face à responsabilidade da missão e ao pouco tempo de que dispúnhamos, ficou acertado, ali mesmo, por telefone,

50 plano elaborado pelo governo, o PIEC, não previa a implantação de universidade estadual em Feira de Santana e sim para Região Sul do Estado, onde estava localizado o pólo agroexportador cacaueiro. Imaginava-se que essa Região, em razão da presença da Ceplac, órgão de fomento e pesquisa da lavoura cacaueira, oferecia as condições cognitivas necessárias para receber a instituição universitária (Santos, 2011). 
que no dia imediato, às nove horas da manhã, nos encontraríamos na Secretaria de Educação [...] (LEITE, 2007, p.421)

\section{Logo depois acrescenta o seguinte comentário:}

Recordo-me bem que, como sempre, cheguei ao encontro com alguns minutos de antecedência. A Profa. Maria Cristina, carinhosamente chamada "Marinita" por todos nós, apresentou-se às 9 horas, exclamando com aquele seu sorriso simpático e característico: - 0 Dr. Geraldo me precedeu! (LEITE, 2007, idem).

Vê-se no discurso de Leite que o mesmo não consegue ocultar o desconforto perante o estranhamento da referida professora para a "missão" ali posta. Naquele momento Maria Cristina Oliveira de Menezes iniciava a sua participação no campo universitário feirense para assumir "a responsabilidade da missão" já iniciada "com alguns minutos de antecedência" provavelmente, Leite referia-se ao tempo passado, e suficiente, que havia já havia credenciado outros agentes que não constavam na composição da referida comissão.

A própria Maria Cristina atesta o seu desencontro em relação ao que estaria ocorrendo naquele momento. Consoante o informado em entrevista para esta pesquisa, a mesma teria sido retirada de seus afazeres em Salvador, onde residia com sua família nuclear e, na ocasião, ocupante do cargo de direção geral do Colégio Manoel Devoto, conforme afirma: “Eu já estava aqui [em Salvador] esse tempo todo sem ir a Feira de Santana. As relações foram restabelecidas com Feira de Santana a partir da Universidade" (entrevista concedida em Salvador, 11/01/2009). Contudo, todos tinham o conhecimento devido de que seu nome lá constava enquanto representante da família do deputado Áureo de Oliveira Filho, que além da atuação no campo de poder, como parlamentar, também era, na ocasião, o principal agente do campo educacional privado da cidade.

Deve-se ressaltar, a partir da leitura da entrevista concedida, que, enquanto professora, Maria Cristina
O. Menezes dispunha, ela própria, de capital cultural para participar do campo universitário que se organizava, pois além da via do poder simbólico originário do campo de poder, que a levou a adentrar o campo "por cima", dispunha de uma forma incorporada de capital cultural herdada de sua família de professores, que era proprietária do principal e tradicional colégio da cidade, o Colégio Santanópolis, até o início dos anos de 1960. Neste sentido a mesma destaca na entrevista referida o seu papel de professora:

\begin{abstract}
Eu sempre estudei em Feira de Santana, fiz clássico e grego, mas ao invés de fazer o curso científico eu fiz o curso clássico. Quando eu terminei era para vir para aqui [Salvador], já estava com tudo preparado para fazer o vestibular e vir. Casei. Tem lá na minha biografia, 1954 [...]. Casei com gerente de banco, fui morar em Itaberaba [...]. Quando eu voltei, meu pai [Áureo Filho], professor de Ciências, disse: "você vai me ajudar". Ele disse: "eu não estou pronto para limpar laboratório ou fazer prática”, então eu assumi essa parte. [...] Dival Pitombo aposentou-se de diretor do Estadual, depois de 21 anos, e queria porque queria que [...] eu assumisse a diretoria do Estadual ou do Gastão. Eu disse não, eu vou ser professora. E fui ser professora (Maria Cristina Oliveira Menezes, entrevista concedida em 11/01/2009).
\end{abstract}

A assunção do ofício de professora se fez pelo cumprimento da herança paterna, embora tivesse optado pelo curso clássico (voltado para as humanidades e as letras). Interessa observar que a referida professora reforça na sua trajetória a opção, uma vez que poderia ter ingressado na rede estadual, também "por cima", como o fez na ocasião de implantação da Universidade - melhor dizendo, conforme "presenteado", legitimado, por herança paterna. Respeitar os ditames paternos parece que foi o destino dessa professora, em virtude dos deslocamentos profissionais que se viu "obrigada" a realizar. O desvio, conforme disse acima, do seu percurso de estudante para o casamento, forço-a a não ingressar na Faculdade de Filosofia da UBA, na época prevista, conforme assinalou:

Eu já tinha quatro filhos quando fiz vestibular [para História Natural] e éramos oito alunos, porque ninguém queria fazer esse curso. E no último ano éramos 
oitenta alunos, mas foi ai que eu me bati com Yara [Cunha], foi aí que estudamos juntas. No último ano eram todas as disciplinas de Educação, então todo mundo, fosse de química, física ou qualquer outra área tinha que cursar junto o último ano. Eu, tanto que, já com dez anos de professora efetiva de Ciências, Dona Leda [Jesuíno] me convidou e eu passei todo tempo ensinando Ciências no Colégio de Aplicação [da UFBA]. Depois fui nomeada diretora geral do Manoel Devoto, está aqui na minha biografia [...]. Eu já estava aqui [em Salvador] esse tempo todo sem ir a Feira de Santana (Maria Cristina Oliveira Menezes, entrevista concedida em 11/01/2009).

A professora Maria Cristina Oliveira Menezes acumularia também capital cultural no seu exercício prático "com dez anos de professora efetiva de Ciência", acrescentados ainda pelo exercício docente junto ao seleto alunado do Colégio de Aplicação da UFBA, e daí, com conhecimento de causa, que a credenciaria, para direção geral do Colégio Manoel Devoto. Donde foi "surpreendida", provável que o tenho sido, pois em outra situação já havia aquiescido ao domínio paterno - melhor, ao poder simbólico exercido pelo mesmo para participar dos ritos de instituição da Universidade de Feira de Santana.

Dias após o início dos trabalhos da comissão que elaboraria o Relatório para constituição da Fundação Universidade de Feira de Santana, o mesmo foi aprovado por unanimidade pela Assembleia Legislativa e resultou na Lei 2.784, sancionada em 24/01/1970. Na constituição do primeiro Conselho Diretor da referida Fundação figurava em primeiro lugar o nome do deputado Áureo de Oliveira Filho, como titular, seguido do de sua filha Maria Cristina Menezes como suplente. Logo na instalação desse Conselho o deputado Áureo Filho renunciava por ser candidato nas eleições que se avizinhavam e, de pronto, assumiu a sua suplente. Selava-se aí participação definitiva da referida professora no campo educacional superior de Feira de Santana. Contudo, foi dessa posição assumida a partir do campo de poder, que a citada agente ingressou como professora na, então, Faculdade de Educação (a Universidade somente seria implantada em 1976). A posição ambígua que antes afirmava o ofício de professora e o de, ao mesmo tempo, representar o campo de poder aparece em seu discurso, conforme é visto nesta passagem:

Eu não fui lá criar a Faculdade [de Educação] quando eu cheguei à Faculdade já existiam dois cursos, o de Letras e Estudos Sociais. Eu fui lá criar o curso de Ciências, do qual fui coordenadora a vida inteira, por dez anos, até levar o curso para a Universidade [...] Foi uma coincidência eu ter ido para Feira e fundado o curso de Ciências, contando com Edvaldo [Boaventura], feirense, que foi Secretário de Educação por acaso, no último ano do governo Luis Viana, e contar com um Ministro da Educação [Eduardo Matos Portela, outro feirense] que fez essa bifurcação do curso de Ciências [em dois departamentos: Biologia e Matemática] (Maria Cristina Oliveira Menezes, entrevista concedida em 11/01/2009)

Sobre a professora Maria Cristina Oliveira de Menezes foi possível perceber no contato com a mesma, em momento mais atual, que o sombreamento das condições sócio-culturais e políticas, que a levaram ao campo instituidor da universidade em Feira de Santana, aparentemente, foi o emblema que a perseguiu ao longo de sua trajetória. Dedução possibilitada a partir da entrevista concedida à pesquisa, cuja principal solicitação da mesma foi a de que neste trabalho não aparecesse com sua fala determinadas "revelações”, que na época pretérita tiveram/teriam complexas repercussões e eram privativas dos agentes no poder, mas na atualidade perderam a força simbólica e política e, neste sentido, são passíveis de serem encontradas em outras fontes orais e documentais.

Enquanto as relações de parentesco permitiam à Maria Cristina livre trânsito no campo universitário que se instalava em Feira de Santana, ampliando-lhe a visibilidade, de outro lado, a primeira professora mencionada, Yara Cunha Pires, fora surpreendida por cerceamento político, com o advento do Al-5, mediante sua fala:

[Trabalhava] Na Faculdade [de Educação] e no Gastão Guimarães. Estava dando aula à noite quando fui 
parada por um rapaz com fardamento militar, que era estudante do Gastão e que me entregou uma correspondência, aí quando eu abri a correspondência meu primeiro choque, eu estava sendo convocada para prestar depoimento no $35^{\circ}$ Batalhão de Infantaria [ em março de 1969] (Yara Cunha Pires, entrevista concedida em 9/03/2009).

Este depoimento resultou em processo que durou mais de dois anos, ao final dos quais the renderam oito meses de prisão por motivos políticos. Há indícios de que durante esse período a atuação dessa professora no campo universitário feirense tenha sofrido sombreamentos nos ritos de implantação da Universidade. Com se sabe, somente a partir dos movimentos de abertura democrática, no final dos anos setenta e início dos oitenta do século passado, os ex-presos políticos passariam a ter mais visibilidade. Deve-se ressaltar, no entanto, que na trajetória dessa professora, é possível inferir que a sombra nunca foi o seu lugar de interesse profissional. Ao contrário: no campo universitário logrou adquirir mais capital inerente ao exercício docente universitário, lança mão do seu aprimoramento acadêmico, cumprindo o Mestrado em Educação (na época o credenciamento mais buscado), bem como, assumiu postos no âmbito das lutas concorrenciais específicos ao campo em foco, conquistando postos de liderança, entre os quais o reitorado da instituição (já na segunda metade da década de 1980).

Sobre a terceira e última professora aqui elencada, Zélia Caribé Nunes Marques, que iniciou sua trajetória no campo universitário feirense como professora da área de Geografia no Curso de Estudos Sociais, da FEEFS, foi lançada ao exercício profissional também a partir do vínculo de parentesco. Sua união matrimonial com José Maria Nunes Marques, pessoa que esteve ao longo de toda sua trajetória no ensino superior feirense vinculado às hostes do poder: foi o primeiro e único diretor da FEEFS (1968-1976), membro do Conselho instituidor da futura universidade, criada em 1970, primeiro pró-reitor acadêmico da implantada Universidade Estadual de Feira de Santana (1976-
1979) e reitor dessa mesma instituição, de 1979 até sua aposentadoria, em 1987. 0 indício é o de que a assunção da vida profissional como docente, por parte da professora em foco, decorreu da trajetória de vida de seu marido quando diretor da Faculdade de Educação. Naqueles tempos de ditadura, o mesmo buscou a organização de um corpo docente que inspirasse confiança e, ao mesmo tempo, fosse qualificado para a instituição, Diante disso, provavelmente, o mais seguro seria contar com os préstimos profissionais de sua própria esposa, o que se efetivou.

Na definição de sua trajetória profissional, a professora Zélia Caribé Nunes Marques atribuiu o seu ingresso no campo universitário feirense à total ausência no interior baiano de professores formados em sua área. Conforme esclareceu:

Eu era a única professora licenciada em Geografia e História no Estado da Bahia para lecionar no interior. A única! Me jogaram todas as Geografias nas minhas costas, ai eu me curvei! Fiz parte da última turma da Faculdade Católica que fez geografia e história juntas, foi a última turma, formada em dezembro de 1959. Depois separaram as turmas, e o prof. Milton Santos era um dos meus professores (Zelia Caribé Nunes Marques, entrevista concedida em 4/12/2009).

De acordo com o ano de formatura, percebe-se o ingresso tardio dessa professora no exercício profissional (formada em 1959, assumiu a docência dez anos depois), evidenciando sua prioridade, ou opção preferencial na dedicação à vida familiar. A mesma é originária da cidade de Feira de Santana e com o casamento fora residir em Salvador, e retornou à cidade natal depois da nomeação de seu marido para assumir cargo público. E o peso sentido nas suas "costas" que a fez "curvar-se", foi descrito da seguinte forma:

Então eu fui para Feira de Santana sem nunca pensar que em dez anos [sem exercer a atividade docente] me jogassem todas as geografias, porque eu era a única candidata. A única, que tinha licenciatura em geografia, não havia concorrentes. Sempre na esperança das colegas Tania Pitombo e Nilza Ribeiro, que começaram 
a fazer o curso para suprir. Tive que esperar quatro anos para entregar as outras geografias e ficar somente com geografia humana. Então [...] fiquei mais aliviada (Zelia Caribé Nunes Marques, entrevista concedida em 4/12/2009).

Esta explicação, algumas vezes repetida, funciona na memória atual como uma justificativa mais que convincente para seu ingresso ao campo universitário feirense. Ou seja, não teve escolha, por ser "a única”, o diretor da FEEFS, seu esposo, só poderia mesmo contar com ela. O seu discurso, na época da entrevista, evidenciava as questões complexas vivenciadas por seu marido no campo educacional superior de Feira de Santana. Em suas lembranças, contudo, o destaque como o momento mais importante de sua vida com o esposo foi o período em que o mesmo era diretor da Escola de Menores de Feira de Santana, longe das amarras do poder - disse na ocasião da entrevista. Parece evidente que a relação de parentesco, o casamento, foi determinante na imposição de seu papel como profissional. 0 sombreamento parece que foi o lugar de destino da professora Zélia Maria Caribé Nunes Marques ao longo de sua trajetória como professora do ensino superior, conforme confessou: “Mas eu nunca gostei muito de sala de aula, então eu fazia um trabalho com muita força, a minha ideia era trabalhar no campo, com pesquisa" (cf. entrevista, em 04/12/2009). Situação que a levou a inovar no trabatho para além da sala de aula, promovendo viagens de estudos de campo com seus alunos. Conforme salientou, o campo, no sentido espacial, era o seu destino: as viagens de campo deram-lhe oportunidade para conhecer o local onde reside, na Chapada Diamantina, na Bahia.

\section{CONCLUSÃO}

A partir dos contatos com as diferentes fontes foi possível perceber os desafios enfrentados por algumas das agentes femininos que participaram da implantação do campo universitário em Feira de Santana. A construção dos processos de identificação e atuação no campo as tornariam irmanadas na luta e ao mesmo tempo distanciadas por força das contradições que circunscreviam a organização daquele espaço institucional, que incluía a posse de tipos diferentes de capital.

As vinculações ao poder político, que concedia cargos e privilégios outros, por força das relações de parentesco, foram determinantes na definição das trajetórias de duas das professoras, embora uma delas estivesse, preferencialmente, nas sombras - sub- metidas aos ditames familiares e masculinos, quase que impondo suas trajetórias profissionais. De modo contrário nos deparamos com trajetória que parece identificada com os interesses de projeto próprio, sinalizando o papel de independência da mulher que ganharia força a partir dos movimentos feministas iniciados nos sessenta do século passado.

Em todos os casos, aquele foi um período da economia nacional em que a mulher, que na maioria das vezes dedicava-se aos afazeres domésticos, passaria a ampliar sua participação no mercado de trabalho. Tanto por questões relativas à emancipação feminina, quanto por necessidade social de complementar a renda familiar, perante um modelo econômico restritivo, que caracterizava a ditadura militar. 


\section{REFERÊNCIAS}

BOURDIEU, Pierre. 0 Poder Simbólico. Tradução: Fernando Tomaz. $2^{\text {a }}$ ed., Rio de Janeiro: Bertrand Brasil, 2005.

BOURDIEU, Pierre. Razões Práticas: sobre a teoria da Ação. Tradução: Mariza Corrêa. São Paulo: Papirus, 1996.

BOURDIEU, Pierre. O Campo científico. ORTIZ, Renato. (org). Pierre Bourdieu. São Paulo: Ática, 1994.

BOURDIEU, Pierre. Escritos de Educação. Maria Alice Nogueira e Afrânio Catani(org.). - Petrópolis, Rio de Janeiro: Vozes, 1998.

SANTOS, Ana Maria F. dos. Ensino Superior na Bahia: aspirações universitárias para Feira de Santana (19501960). Anais $19^{\circ}$ EPEEN, João Pessoa, 2009.

SANTOS, Ana Maria F dos. Uma Aventura Universitária no Sertão Baiano: da Faculdade de Educação à Universidade Estadual de Feira de Santana. Tese doutorado, UFBA, 2011.

GINZBURG, Carlo. Relações de Força: História, retórica, prova. São Paulo: Companhia das Letras, 2002.

THOMPSON, Alister. Recompondo a memória: Questões sobre a relação entre a História Oral e as memórias.

Projeto História. São Paulo: EDUC, n 15, Abril de 1997.

Recebido em: 15 de julho de 2013

Avaliado em: 9 de agosto de 2013

Aceito em: 26 de agosto de 2013

1 Este trabalho foi apresentado com alterações no III Seminário Nacional de Gênero e Práticas Culturais, João Pessoa, outubro de 2011. Os dados aqui utilizados foram levantados na minha pesquisa de doutorado, intitulada Uma Aventura Universitária no Sertão Baiano: da Faculdade de Educação à Universidade Estadual de Feira de Santana, defendida em 2011.

2 Doutora em Educação pela UFBA, professora adjunta do Departamento de Educação da Universidade Estadual de Feira de Santana. Endereço: Rua Bebedouro, s/n, casa 4, CEP 44082-030 Feira de Santana Bahia; E-mail: omfontes@uol.com.br. 